\title{
Expression of a thermostable xylanase gene from Bacillus coagulans ST-6 in Lactococcus lactis
}

\begin{abstract}
Aims: The aim of the study is to evaluate whether xylanase can be used as a potential reporter gene for cloning and expression studies in Lactococcus. Methods and Results: The $750 \mathrm{bp}$ xylanase gene was amplified and subcloned into the unique NheI restriction enzyme site of pMG36e and subsequently transformed into competent Escherichia coli XLI-blue MRF cells and Lactococcus lactis cells. Bacterial culture containing pMG36e-Xy has an enzyme activity of $390 \mu \mathrm{g}$ xylose ml-1 culture $30 \mathrm{~min}-1$, respectively, when compared with $40 \mu \mathrm{g}$ xylose ml-1 culture $30 \mathrm{~min}-1$ for the negative control (plasmidless strain). Conclusions: The thermostable xylanase gene was successfully expressed in both E. coli and L. lactis. The activity of xylanase can be easily detected by the formation of visible clearing zones around the transformed colonies on Remazol Brilliant Blue-Xylan (RBB-Xylan) agar media. However, there were some significant differences in the optimum growth temperature and plasmid stability in the new clones. Significance and Impact of the Study: The constructed reporter vector has the potential to be used as a reporter system for Lactococcus as well as E. coli, and it is an addition to the pool of lactococcal vector systems.
\end{abstract}

Keyword: cloning, expression, Lactococcus, xylanase 